\title{
MANEJO DE RESIDUOS SOLIDOS EN LA CIUDAD DE TACNA
}

\author{
Responsable : Ing. Gregorio Pedro Tejada Monroy \\ Miembro : Lic. Mario Alberto Matos Peña
}

\section{RESUMEN}

Es necesario concientizar a la ciudadania para que contribuya a un adecuado manejo de los residuos sólidos, desde nuestros hogares hasta la disposición final de los mismos en el relleno sanitario, fomentando el desarrollo de tecnologias y programas sociales para disminuir la contaminación de nuestro medio ambiente.

El presente trabajo de Investigación describe el Manejo de los Residuos Sólidos en la Ciudad de Tacna y propone alternativas para aprovechar los mismos generando beneficios: como practicar la 3 Rs (Reduce, Reusa y Recicla) y proyectar una Planta de Separación y Reciclaje de Residuos Sólidos en nuestra Ciudad.

\section{ABSTRACT}

It's necessary that citiezens become sonsciores that the have to use solid waste in a conect way so they can contribyte to improve this situation.

This have to stait ou homes and contoinue until the waste finish in a healtly placeimproving this way the development of technology and social programs to decrease pollution in our enviroment.

This research work decreases the use of solid waste in tacna city and it also proposes alternatives to to take adventage of them. And in this way generate deneficts to all of us. One way is ractice the three R's: Reduce, Recycle and re-useand plan a place where solid was could be separated and re-cycle.

\section{INTRODUCCIÓN}

Uno de los principales problemas que enfrenta la ciudad moderna es el manejo de la elevada generación de residuos domésticos, industriales y comerciales. La Ciudad de Tacna, por ser una zona altamentecomercial y con proyecciones futuras de incremento comercial y turístico, no es ajena a este problema. En la ciudad de Tacna las fuentes de basura son variadas, pero la mayor cantidad de residuos sólidos se produce en los hogares y su mala disposición origina la contaminación de nuestras calles, nuestros parques y lugares públicos.

A diario también observamos personas informales que revisan los botes y bolsas de basura para recolectar desperdicios de alimentos, botellas de vidrio, botellas descartables, cartones, latas, es decir, recuperando todo lo que para el resto de gente es inservible. Pese a que son muchas las causas que influyen en esta problemática, se puede destacar como las principales: los malos hábitos de las personas con relación a la disposición de los desechos y la falta de conocimiento acerca del uso que les pueden dar, la cantidad cada vez mayor de residuos que genera la población y la falta de lugares adecuados para la disposición final de la basura y para su reciclaje o reutilización ordenada y reglamentada.Sabemos que la basura actualmente es una preocupación para la comunidad como para el Municipio cuya labor es deshacerse de ella, pero a la vez puede ser un recurso del cual podemos obtener ganancias y para ello tenemos que generar conciencia en las familias.

\section{ANTECEDENTES DELPROBLEMA}

Al revisar la bibliografia hallamos algunos libros que tienen que ver de alguna manera con nuestro trabajo de investigación:

"Programa de Reciclaje de Papel y Cartón en 600 centros educativos a nivel nacional" (programa recicla 2000), a cargo del Instituto de Promoción de la Economía Social (IPES) y el Consejo Nacional del Ambiente (CONAM). El objetivo del programa era sensibilizar, capacitar y promover cambios de actitudes en la comunidad educativa respecto al cuidado y conservación del ambiente. Es en 1994 cuando se inician las primeras experiencias piloto en el tema de Educación Ambiental, referidas a sistemas de reciclaje en la fuente en colegios, oficinas y organizaciones de base; y a partir de 1995 se introduce el enfoque Minimización de Residuos o 3 Rs (Reduce, Reúsa y Recicla).

Reciclaje de los Residuos Sólidos en Centros Educativos del Cono Norte, proyecto que se realizó en los distritos de Ancón, Carabayllo, Comas y los Olivos del Cono Norte de Lima, a cargo de la ONG Alternativa. Entre los resultados de este proyecto tenemos: Recolección y tratamiento del $70 \%$ de residuos sólidos generados en cada centro educativo, 5 000 escolares sensibilizados segregan los residuos sólidos en sus centros educativos.

\section{1) Definición de Términos Básicos}

Compost: Es una importante alternativa para aprovechar los residuos orgánicos. El compost no es exactamente un abono sino un regenerador del suelo.

El compost se produce cuando se somete el material orgánico a un proceso de descomposición natural manteniendo las condiciones bajo control.

El proceso dura meses y luego podemos utilizar el compostpara agregarloal suelo.

Incineración: Es la combustión directa y controlada de los residuos, que produce finalmente gases (principalmente dióxido de carbono y agua) y cenizas sólidas. Se realiza en hornos que alcanzan muy altas temperaturas. Los gases producidos deben ser filtrados para no contaminar la atmósfera, demandando altos costos. La incineración reduce en un $95 \%$ el volumen inicial de residuos, por eso se aplica en países 
desarrollados con poca disponibilidad de espacio. En nuestro país esta tecnologia sólo se aplica a los residuos hospitalarios.

La incineración no debe ser confundida con la quema de basura a cielo abierto, que es extremadamente nociva para el ambiente y la salud. De ella se libera unos gases llamados dioxinas que son cancerigenas y otro tipos de contaminantes.

\section{2) Ley General de Residuos Sólidos Nㅜ 27314}

Ley que establece derechos, obligaciones, atribuciones y responsabilidades de la sociedad en Su conjunto, para asegurar una gestión y manejo de los residuos sólidos, sanitaria y ambientalmente adecuada, con sujeción a los principios de minimización, prevención de riesgos ambientales y protección de la salud y el bienestar de la persona humana.

\section{Manejo de Residuos Sólidos}

Toda actividad técnica operativa de residuos sólidos que involucre manipuleo, acondicionamiento, transporte, transferencia, tratamiento, disposición final o cualquier otro procedimiento técnico operativo utilizado desde la generación hasta la disposición final.

\section{Medio Ambiente}

Es el conjunto de componentes físicos, quimicos y biológicos necesarios para la supervivencia de cada una de las especies.

\section{Minimización}

Acción de reducir al mínimo posible el volumen y peligrosidad de los residuos sólidos, a través de cualquier estrategia preventiva, procedimiento, método o técnica utilizada en la actividad generadora.

\section{Reaprovechar}

Volver a obtener un beneficio del bien, artículo, elemento o parte del mismo que constituye residuo sólido. Se reconoce como técnica de reaprovechamiento el reciclaje, recuperación o reutilización.

\section{Reciclaje}

Toda actividad que permite reaprovechar un residuo sólido mediante un proceso de transformación para cumplir su fin inicial u otros fines.

\section{Recuperación}

Toda actividad que permita reaprovechar partes de sustancias o componentes que constituyen residuo sólido.

\section{3) Relleno Sanitario}

Instalación destinada a la disposición sanitaria y ambientalmente segura de los residuos sólidos en la superficie o bajo tierra, basados en los principios y métodos de la ingenieria sanitaria y ambiental. Un relleno sanitario debe estar acondicionado para:

- Controlar y recuperar los gases que salen cuando se descompone la basura (en especial $\mathrm{CO}_{2}$ (dióxido de carbono) y $\mathrm{CH}_{4}$ (metano, gases responsables del efecto invernadero).

- Impedir que los lixiviados (jugos contaminantes que se producen de los residuos en descomposición) se filtren hasta las aguas subterráneas contaminándolas.

- Controlar los malos olores.

- Evitar la proliferación de insectos y roedores.

Si el relleno no cumple con estos requisitos, se convierte en un botadero, que es un gran espacio de tierra, donde se acumula toda la basura sin ningún control ni tratamiento. Es fuente de contaminación del suelo, las aguas subterráneas, y el aire.

\section{4) Residuos Sólidos}

Son residuos sólidos aquellas sustancias, productos o subproductos en estado sólido o semisólido de los que su generador dispone, o está obligado a disponer, en virtud de lo establecido en la normatividad nacional o de los riesgos que causan a la salud y el ambiente, para ser manejados a través de un sistema que incluya, según corresponda, las siguientes operaciones o procesos:

Minimización de residuos
Segregación en la fuente
Reaprovechamiento
Almacenamiento
Recolección
Comercialización
Transporte
Tratamiento
Transferencia
Disposición final
Esta definición incluye a los residuos
generados por eventos naturales.

\section{5) Reutilización}

Toda actividad que permita reaprovechar directamente el bien, artículo o elemento que constituye el residuo sólido, con el objeto de que cumpla el mismo fin para el que fue elaborado originalmente.

\section{6) Segregación}

Acción de agrupar determinados componentes 0 elementos fisicos de los residuos sólidos para ser manejados en forma especial.

\section{7) Tipos de Residuos Sólidos}

Orgánicos: Son los productos de origen biológico que provienen de los seres vivos (ejemplo: cáscaras de frutas y vegetales, cenizas, café o té, aserrín, podas del jardin, restos de las chacras y árboles, estiércol del ganado y similares).

Inorgánicos: Son los productos que no son de origen biológico. Son generados por las grandes actividades industriales y de consumo del hombre (ejemplo: plástico, vidrio, latas, papel y similares).

Especiales: Generalmente tienen un origen industrial, y su presencia en el ambiente puede ser de alto riesgo 
para los seres vivos. Son muy variados: oxidantes, corrosivos, inflamables, explosivos, tóxicos y radiactivos.

\section{8) Tiempo de Descomposición de Algunos Residuos Sólidos}

El proceso de descomposición de los residuos sólidos urbanos por los factores ambientales como la lluvia, el oxígeno del aire, la luz del sol y los microorganismos que viven en el suelo, es muy lento, por lo que se van acumulando cada vez en mayores cantidades:

- Un resto vegetal tarde unos 3 meses en descomponerse.

- El papal tarde 1 año en ser reincorporado a la naturaleza.

- Una colilla de cigarrillo se degrada en 1 a 2 años.

- Un vaso descartable de plástico tarde entre 200 y 450 años en degradarse.

- Las latas de aluminio necesitan 500 años para descomponerse.

- Una botella de vidrio requiere 1 millón de años para descomponerse

- Un pila tarda más de 1000 años, y contiene mucho contaminantes.

Después:

- Si los residuos se queman al aire libre, se contamina el aire.

- Si se entierran, contaminan el suelo y las aguas subterráneas.

- Si se acumulan junto a rios, mares y lagos, se contamina el agua y se afecta la fauna acuática.

- Si los residuos se disponen mal, generan proliferación de plagas, roedores, hongos, bacterias y otros microorganismos.

- Crean incendios por combustión espontánea de los residuos.

\section{9) Tres Rs:}

- Reduce: Evita todo aquello que genere un desperdicio innecesario.

- Reúsa:Vuelve a usar un producto o material varias veces. Debemos darle la máxima utilidad a los objetos sin la necesidad de destruirlos 0 deshacernos de ellos.

- Recicla: Utilizar los mismos materiales una y otra vez, reintegrándolos a otro proceso natural o industrial para fabricar otros productos.

\section{MATERIALY MÉTODOS}

\section{1) Material de Estudio}

La población de estudio está integrada por los ciudadanos de la ciudad de Tacna, integrada por los distritos de Tacna, Alto de la Alianza, Ciudad Nueva, Pocollay y Gregorio Albarracin. Para la selección de la muestra de estudio se tomó las zonas donde se generan, almacenan, recolectan y comercializan la mayor cantidad de Residuos Sólidos, ubicados en los distritos de Tacna, Gregorio Albarracín y Alto de laAlianza.

\section{2) Metodología}

Se diseñó y aplicó encuestas en zonas puntuales de la ciudad de Tacna identificadas como problemáticas (distritos de Tacna, Gregorio Albarracin y Alto de la Alianza).

\section{RESULTADOSYDISCUSION}

\section{1) Encuesta}

\section{Cuadro $\mathrm{N}^{\circ} 01$}

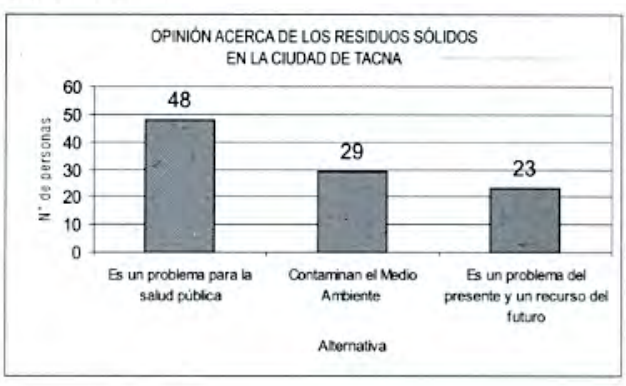

\section{Cuadro $\mathrm{N}^{\circ} 02$}

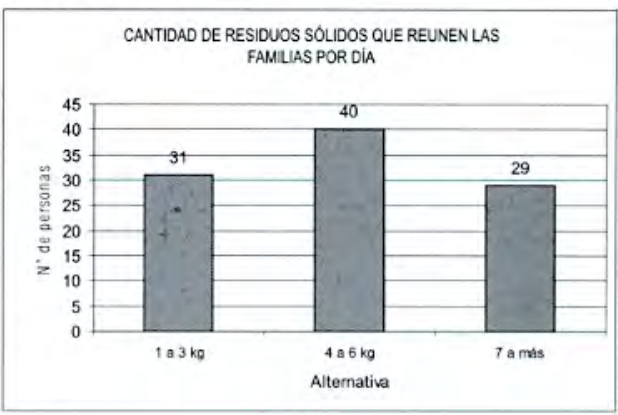

\section{Cuadro $\mathrm{N}^{\circ} 03$}

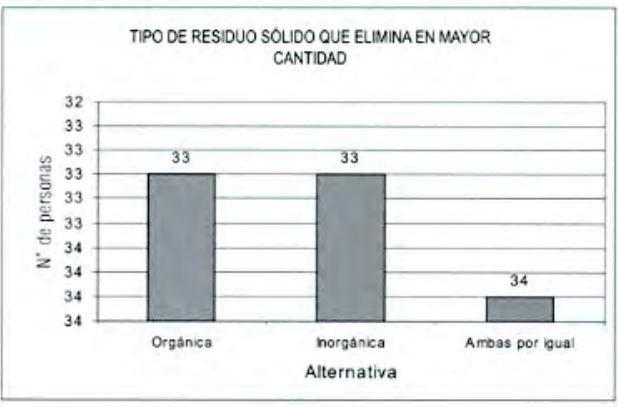

\section{Cuadro $\mathrm{N}^{\circ} 04$}

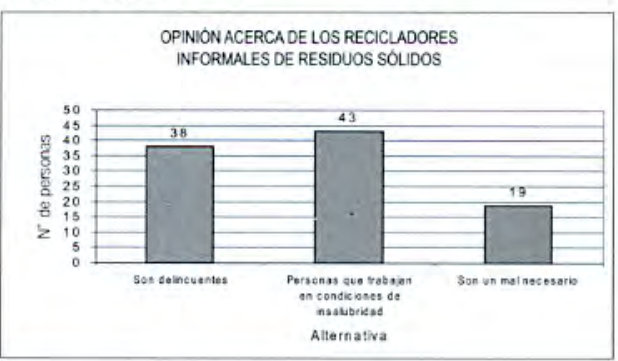




\section{Cuadro $\mathrm{N}^{\circ} 05$}

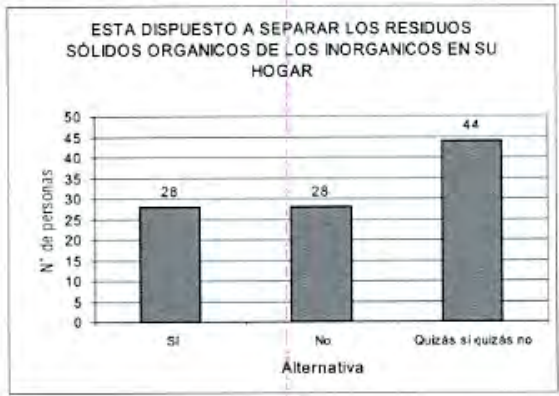

\section{Cuadro $N^{\circ} 06$}

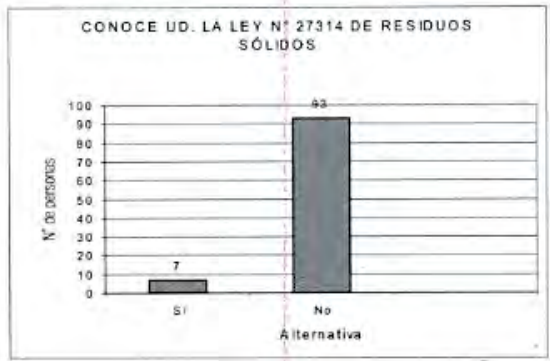

Cuadro $\mathrm{N}^{\circ} 07$

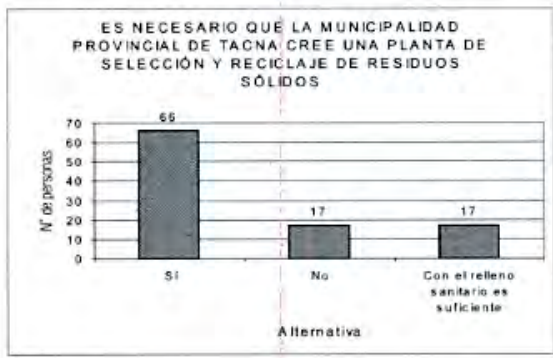

\section{2) Discusión}

La mayoria de los pobladores de la ciudad de Tacna considera que los Residuos Sólidos son un problema para la salud publica y contaminan el medio ambiente pero pocos consideran a los Residuos Sólidos como un recurso que genere beneficios económicos a futuro. De las 280,40 toneladas/dia de Residuos Sólidos que produce la ciudad de Tacna, aproximadamente el $90 \%$ va directamente al relleno sanitario y el $10 \%$ es comercializado por los llamados "recicladores". En la ciudad de Tacna hay cuatro empresas comercializadoras de Residuos Sólidos registradas en la Dirección General de Salud Ambiental del Ministerio de Salud de la 150 que existen a nivel nacional. La mayoria de la población de Tacna desconoce la Ley de Residuos Sólidos N 27314. La mayoria de la población de Tacna opina que es necesario una planta de selección y reciclaje de Residuos Sólidos en la Ciudad de Tacna.

\section{CONCLUSIONES}

1. Un elevado porcentaje de Residuos Sólidos es eliminado en el relleno sanitario de nuestra ciudad, el cual podria ser reaprovechado para generar recursos en beneficio de la Comunidad Tacneña.

2. Presencia y aumento de segregadores informales, a los cuales se les considera muchas veces como delincuentes.

\section{RECOMENDACIONES}

Es necesaria la sensibilización de los pobladores de la ciudad de Tacna para que asuman sus responsabilidades como generadores de Residuos Sólidos. De acuerdo con la Ley de Residuos Sólidos №27314 que indica como obligaciones de la ciudadania en su articulo 41: "Almacenar los residuos sólidos con sujeción a las normas sanitarias y ambientales, para evitar daños a terceros y facilitar su recolección".

Se debe implementar campañas de educación ambiental a fin de disminuir las cantidades de Residuos Sólidos, a través del cumplimiento de las 3 Rs. (Reduce, Reúsa y Recicla).

Incentivar la formación de empresas para la transformación de los Residuos Sólidos, bajo un enfoque de prevención de la contaminación, mejora continua y cumplimiento de normas y leyes.

Es necesario que se planifique e invierta en un centro de separación y reciclaje de Residuos Sólidos en la ciudad de Tacna, que permitiria ingresos económicos para autosostener y mejorar la limpieza en la ciudad de Tacna.

\section{BIBLIOGRAFÍA}

Agenda 21 De Rio De Janeiro. (1992 1998) (Julio 2003).

Brack F.gg, Antonio; Mendiola, Cecilia.-Ecologia del Perú, ASD Páginas 316 - f325. Editorial Bruño. Lima, 2000.

Cases I Associats. Enciclopedia visual de la ecología. Empresa editoraASD,El Comercio S.A. 1996

Municipalidad de Santiago de Surco. (2002). Escuela Interante de Educacion Ambiental (e.i.d.e.a.). Lima-Perú.

Municipalidad Provincial de Tacna. (2004). Plan Integral de ASD Gestión Ambiental de Residuos Sólidos de la Ciudad de Tacna. Perú.

Pasco Alberto Quevedo Font. (1999), Desarrollo Sustentable en elASD Perú, Editorial Agenda Perú. Lima.

Rodríguez Becerra; Manuel, Espinoza Guillermo. (2003) ASDGestión ambiental en América Latina y el Caribe: Evolución, Tendencias y ASDPrincipales Prácticas Banco interamericano de desarrollo BID ASD Departamento de Desarrollo Sostenible España.

Romano Yalour, Margo. (1999) Desarrollo Sustentable . Revista de ASD Medio Ambiente REDESMA. La Paz, Bolivia.

Universidad Marcelino Schampagnat. (2000). II Congreso ASDNacional de Educación Ambiental". Lima. 